\section{Profitability of Artichoke Growing in the Mediterranean Area}

\author{
Filippo Sgroi ${ }^{1}$, Mario Foderà, Anna Maria Di Trapani, \\ Salvatore Tudisca, and Riccardo Testa \\ Department of Agricultural and Forestry Sciences, University of Palermo, \\ Viale delle Scienze, Edificio 490128 Palermo, Italy
}

Additional index words. Cynara scolymus, costs, economic analysis, economic sustainability

\begin{abstract}
Cultivation of artichokes for production is significant in the Mediterranean Basin. Italy represents an important productive hub and in this context, Sicily has been one of the foremost production areas. Artichoke production is a stable element of either specialized or mixed production systems in the region. However, due to the economic recession and increasing imports of artichokes from North African countries, many companies are undergoing crisis, with concerns for the negative impact on the socioeconomic fabric, in terms of the rising unemployment an eventual collapse of this specific activity would determine. According to the theory of economic development, a prerequisite of a territory's development is that its economic enterprises be competitive. Ensuing from this hypothesis, this article analyzes the profitability of artichoke production in the Mediterranean. The study was conducted in Sicily, an island in the heart of the Mediterranean, where its cultivation is a long-standing tradition. Our results showed a low profitability for artichoke cultivation in relation to the unfavorably high production costs, whereas the low market prices also reflect the competition from countries of North Africa.
\end{abstract}

Artichoke (Cynara scolymus L.) is an ancient perennial plant species native to the Mediterranean Basin and known since the first century AD. The Arabs played an important role in its diffusion in the southern Mediterranean area during the Middle Ages.

Artichoke is particularly widespread in the Mediterranean Basin, where the climate is characterized by warm summers and mild winters (D'Asaro and Grillone, 2012; Leskovar et al., 2013).

The edible portions of the artichoke are then given by the lower portions of the bracts and the receptacle (Conti et al., 2005).

Nowadays, the emerging life style that favors healthy and novelty foods indicates a change in that trend that should be seen by the industry as an opportunity for expansion (Goubran et al., 2005). In this context, artichoke significantly contributes to the Mediterranean agricultural economy, with Italy being one of the main producers.

The autumn-winter production is normally destined to the fresh consumption, while that harvested during the spring period is used by the processing industry (Del Nobile et al., 2009).

\footnotetext{
Received for publication 17 June 2015. Accepted for publication 12 July 2015 .

This study is a result of the full collaboration of all the authors. However, M. Foderà wrote the introduction, A.M. Di Trapani wrote Economic Literature, R. Testa wrote Material and Methods, F. Sgroi wrote Results, and S. Tudisca wrote Conclusions.

${ }^{1}$ Corresponding author. E-mail: filippo.sgroi@ unipa.it.
}

According to the latest available data (FAO, 2015), the world surface area of artichoke cultivation in 2012 amounted to 125,351 ha, yielding 1,634,219 t. Over the last decade (2003-2012), there has been an increase in world production $(+27.8 \%)$, while the total surface has remained substantially unchanged (+1.6\%) (Fig. 1).

The Mediterranean Basin in 2012 was the main area of artichoke cultivation with 93,875 ha $(74.9 \%$ of the total world area) and a production of $1,208,307 \mathrm{t}(73.9 \%$ of the total production) (Fig. 2).

Among Mediterranean countries, Italy, Egypt, and Spain account for $55.4 \%$ of the total area planted with artichoke worldwide and $58.2 \%$ of the total harvest.

As for surface area under artichoke, Italy is foremost (35.593 ha), followed by Egypt (17.895 ha) and Spain (16,000 ha). Notwithstanding, Egypt is the single largest producer, with its $387,704 \mathrm{t}$, followed by Italy $(364,871 \mathrm{t})$ and Spain $(199,100 \mathrm{t})$.

Among the major producing countries, it is interesting to note the increase registered by Egypt in the course of the last decade, both in terms of planted surface $(+210.6 \%)$ and yield $(+251.3 \%)$, which allowed the African country to outrank Italy in 2012, in terms of yield, albeit remaining second for surface area of production in the world. Spain and Italy, on the other hand, have registered a decline in terms of both planted surface $(-16.2 \%$ and $-28.7 \%$, respectively) and harvested production ( $-35.0 \%$ and $-16.2 \%$ respectively).

The increase, recorded in recent years, on the part of Egypt is largely the result of increased competitiveness due to lower labor costs, but also to continuing investments to modernize the production chain, targeting not only the cultivation techniques, but also the marketing strategies aimed at increasing exports of the product.

In Italy, most of the production is concentrated in the southern regions and, among these, Sicily is the front-runner $(32.8 \%$ of Italian production) (ISTAT, 2015).

So, since economic sustainability is the most important factor for the adoption of a crop (Beckford et al., 2011; Spiertz, 2013), to better understand the profitability of Sicilian artichoke production, an economic analysis in a case study was performed. Recognition of real costs and profitability of artichoke growing, in fact, are vital for the entrepreneur that has to produce in an increasingly globalized and competitive market.

\section{Economic Literature}

It is widely known that the offer is the aggregate result of a host of individual production units competing among themselves, with each offering a tiny percentage of the total production of largely undifferentiated goods (Messori, 2007). Agricultural production is seasonal and typically not subject to short-term variations. In fact, prices do not depend on production costs, but are rather an expression of supply and demand. Under such conditions, the greater the offer, the faster the decline in agricultural prices (Prestamburgo and Saccomandi, 1995). The agricultural sector is characterized by a myriad of businesses whose range extends no further than the first stage of the supply chain. It is a case of an industry that, given the small average size of its enterprises, too often fails to cover every stage of the production chain; as such, market shortages (that is quantity demanded greater than quantity supplied), although increasing prices, tend to be of little avail to companies inasmuch as they lack the leverage over supply needed to reap any real benefit. All this creates price instability and lessens entrepreneurs' bargaining power and consequently the income to be earned from the relative entrepreneurial activities (Cecchini et al., 2010; Monarca et al., 2014). A farm's lesser or greater capacity for generating income derives, apart from its conduct with respect to the market, from the constraints it has to deal with while going about its business (Lanfranchi et al., 2014; Lanfranchi and Giannetto, 2014). These constraints are ascribable to the very structure of the undertaking as well as to the external environment. Internal constraints include the farm's production capacity (in both qualitative and quantitative terms), financial capacity, organization, and finally, its expense behavior, i.e., the relationship between expenses and revenues (Bonazzi and Iotti, 2014; Iotti and Bonazzi, 2014). The latter depends on the cost structure and business revenues, particularly with regard to the interrelationship between fixed and variable costs and revenues. Indeed, profitability is a farm's aptitude to cover the costs by achieving revenues so as to ensure an adequate return on the inputs wielded in economic units, 


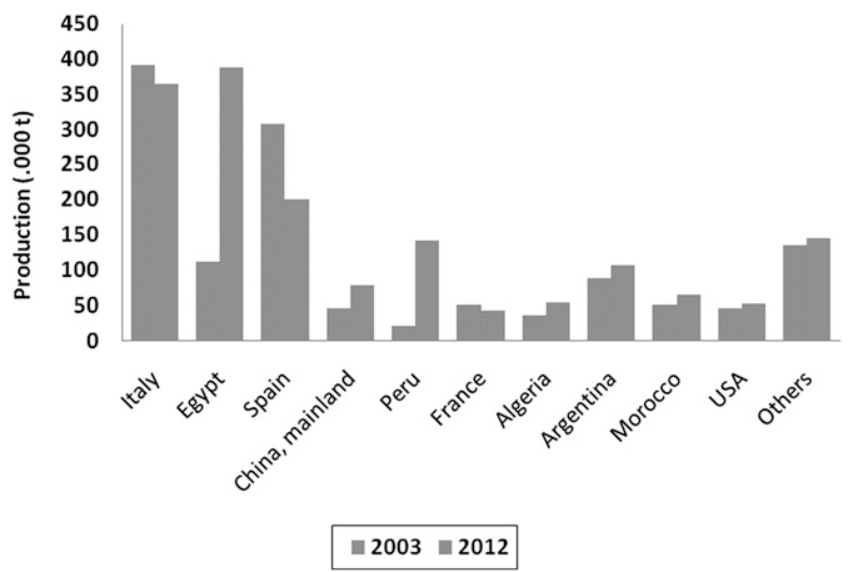

Fig. 1. Production of artichokes in the last decade.

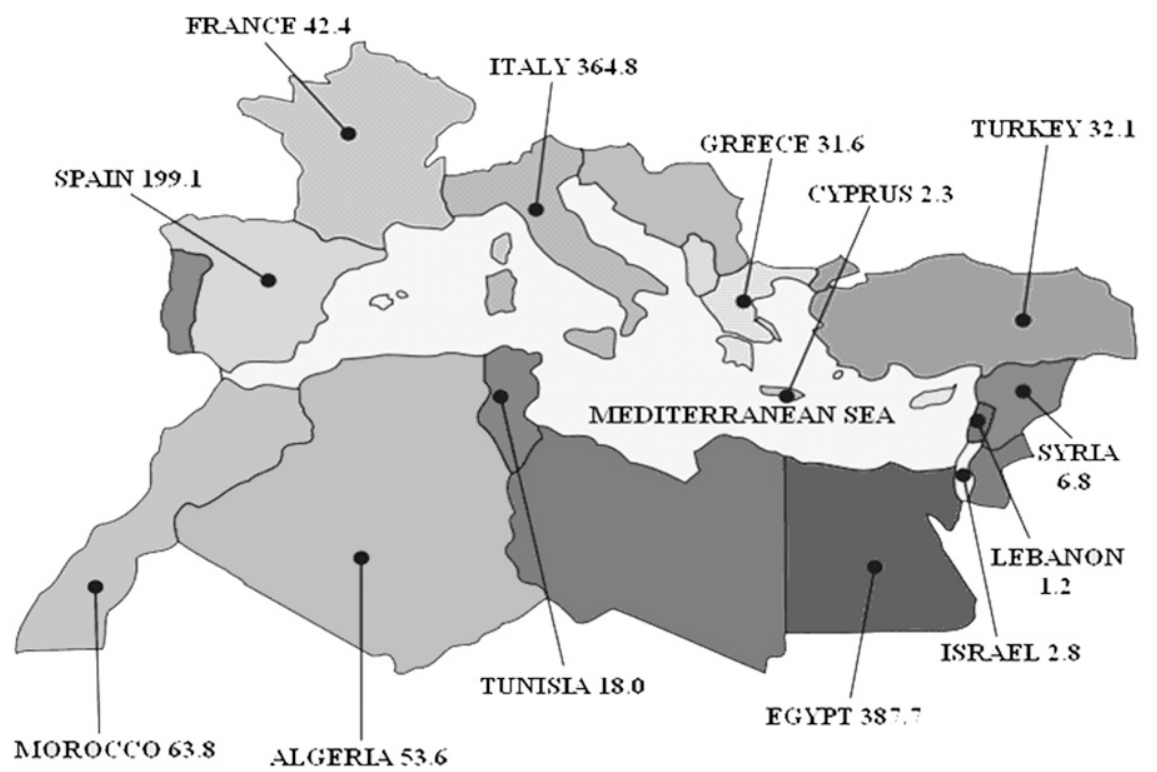

Fig. 2. Producer countries of artichokes in the Mediterranean area in $2012(0.000 \mathrm{t})$.

while affording the proprietor commensurate proceeds. The comparison of revenues and costs is indispensable, in both budget and balance sheet, to evaluate the effects of choices in cost-volume-profit analyses (Chinnici et al., 2014). In fact, for proper business management, one must understand which variables of the production process to act upon, or, if feasible, which products to abandon and which to start producing (Lupo, 2015a, 2015b, 2015c). The latter aspect comprises the crucial planning horizon where the entrepreneur can choose among all technically viable solutions; in fact, in the long term, the entrepreneur can modify all the factors of production. From an agronomical point of view, the choice depends on the pedological and climatic conditions and, assuming one wants to orient production toward herbaceous crops, the selection of a suitable crop rotation system. However, after the production planning stage, matters lapse back into the short term, that is, into free market conditions where at least one factor becomes fixed. From an economic viewpoint, once a culture has been chosen, one can act only on subset factors of production, namely the variable ones. In light of the above, the aim of this work was to measure corporate profitability.

\section{Materials and Methods}

For the purposes of our study, an economic survey was conducted on a representative case study of a farm producing artichokes in open field in western Sicily. The case study selected appears consistent with the objectives of the study, i.e., to determine the profitability of artichoke crops for the farm (Dana and Dana, 2005). In particular, the characteristics taken into consideration for the case study were those most frequently observed in Sicilian fresh vegetable farms according to the most recent Italian Agricultural Census data (ISTAT, 2012), i.e., small farm size, farm managed directly by farmer's family, low mechanization of farming operations, and local sales modality. The surveyed farm had an area equal to 1.50 ha, entirely planted with 'Spinoso violetto di Palermo' artichoke (Fig. 3). This spined variety has a small flower head and the exterior bracts are green with shades of violet (Cirivello et al., 2005). Production begins at the end of November and finishes in April.

To estimate the profitability of the crop (per hectare and per flower head), costs and revenues were determined and all technicaleconomic data have been collected by means of a face-to-face questionnaire with farmer, as well as in other studies (Ataseven et al., 2014). Costs and revenues are based on the prices for 2014, provided directly by the entrepreneur interviewed. The questionnaire included several questions and was divided into two main parts. The first gathered structural and management data (farm size, artichoke area, farm investments, sales modality of production), while the second focused on the artichoke production process (farming operations for crop growing with inputs and human labor required) and farmer's revenues (yield, sales price).

The total cost of production of artichoke growing was broken down into variable and fixed costs (Engindeniz, 2007), as follows:

$$
\mathrm{TC}=\mathrm{VC}+\mathrm{FC}
$$

where TC represents total cost of production, $\mathrm{VC}$ is variable costs, and $\mathrm{FC}$ represents fixed costs.

The former category included the costs of farming operations required during the productive process: tilling, setup and leveling of irrigation system, purchase of ovules, soil management, fertilization, irrigation, crop treatments, harvesting, packaging, transport, mediation (the fee that the farmer pays to wholesalers for the sales of artichoke), maintenance and repairs of durable capital, and interest on current costs. Every cost item was determined by summing up (where present) labor costs required for farming operations and expenditures for materials and services coming from outside the farm related to the production process. Interest on current costs was determined by charging a simple interest rate of $5 \%$, anticipated for 4 months on average, relative to the period of artichoke production and marketing.

In regards to fixed costs, they included depreciation quotas of durable capital (irrigation equipment, agricultural machines, farming buildings), administration expenses (compensation for intellectual work), interest on both durable capital and land value, and taxes.

To determine revenues, or gross production value (GPV), of artichoke growing, the annual average yield was multiplied by the annual average selling price:

$$
\mathrm{GPV}=p \cdot y
$$

where GPV is the gross production value, $p$ represents the annual average selling price, and $y$ is the annual average yield. In particular, for annual yield, to obtain a value independent of positive or negative yearly fluctuations, an average of the preceding 4 years (2010-14) was considered, obtaining a yield equal to 6.5 flower heads/plant. These 


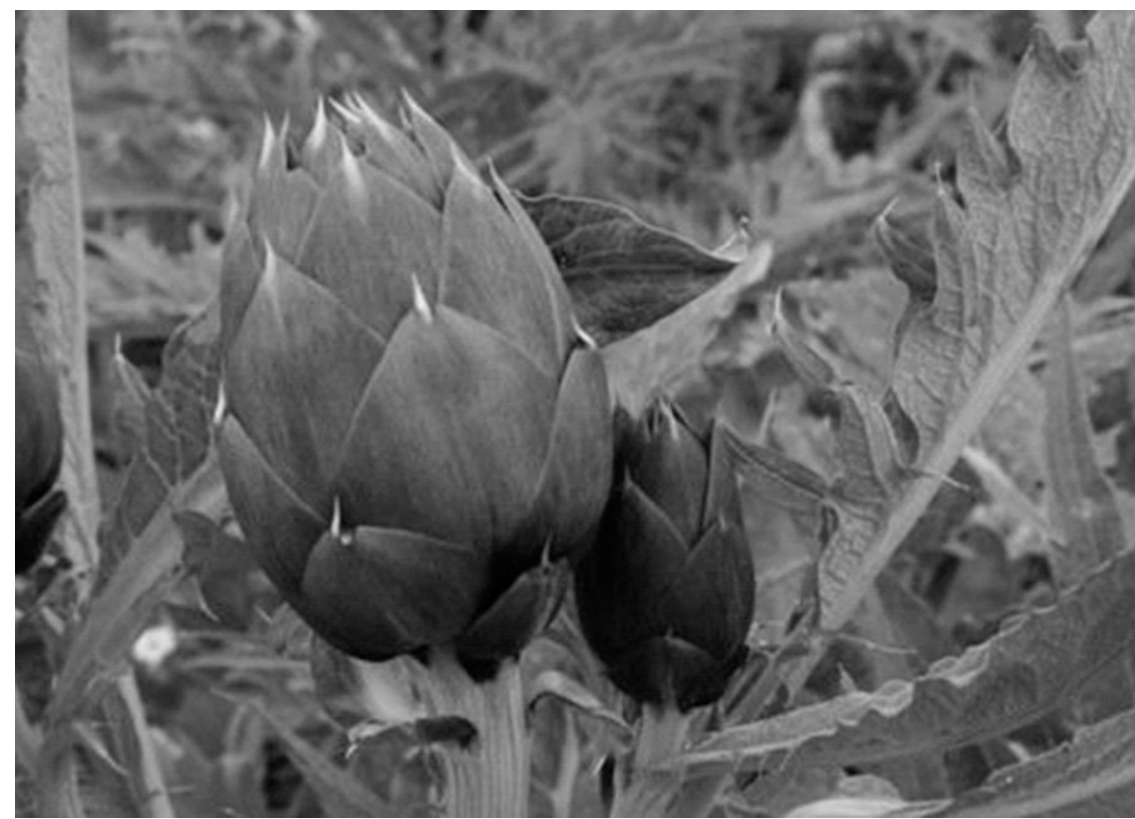

Fig. 3. 'Spinoso violetto di Palermo' artichoke.

values refer to the volumes produced by the farm itself, as well as to a parallel comparative analysis conducted on local operators in the territory of the study. For selling price, a value of $0.38 € /$ flower head was applied, considering the average price recorded in the main wholesale markets of Sicily in the year 2014 .

Finally, the profit of artichoke growing was calculated by subtracting total production cost from GPV, as follows:

$$
\mathrm{II}=\mathrm{GPV}-\mathrm{TC}
$$

\section{Results}

As can be discerned from Table 1, the total cost of production was $17,119.75 € /$ ha while the per-unit cost was $0.37 € /$ flower head (Table 1).

Variable costs represented the category having the greatest impact, comprising $80.9 \%$ of the total cost of production. Of the latter costs, the principal item was that spent for harvesting, which alone absorbed $21.3 \%$ of total cost of production, followed by the purchase and planting of ovules (17.9\%). This burdensome expenditure was due to the fact that all companies recur to manual harvesting and planting procedures.

Among fixed costs, instead, the main item was represented by price for by interest on durable capital and land use $(1,150.00 € / \mathrm{ha})$, followed by depreciation of durable capitals (850.00 €/ha).

Profit amounted to $520.99 € /$ ha, i.e., 0.01 $€ /$ flower head. These results revealed a very modest profitability of the crop, deriving from a GPV equal to $17,640.74 € /$ ha.

In particular, if prices were to drop below $0.37 € /$ flower head, profits would break even. Taking into account the fluctuations that selling prices can undergo during the harvesting phase, as well as the variability of yields, a sensitivity analysis was performed to analyze how the economic results of the enterprise would vary accordingly.

In particular, selling price values of 0.25 and $0.30 € /$ flower head were considered. The simulation resulted in a loss ranging between $-4,663.70 € /$ ha $(-0.10 € /$ flower head $)$ and $-2,669.44 € /$ ha $(-0.06 € /$ flower head $)$.

In sum, from the results of the accounting analysis for the crop, it is noteworthy that only selling prices in excess of $0.37 € /$ flower head manage to remunerate the factors of production.

\section{Conclusions}

Our study on artichokes grown in Sicily highlighted a low profitability of the crop, due to unyielding production costs and low selling prices. This situation is determined by the staunch antagonistic competition exerted by the countries of North Africa, whose production costs are more contained, allowing their farmers to lower prices below the production costs sustainable by competitors in Sicily, yet continuing to generate positive margins of profit. Another factor that affects the meager competitiveness of companies is the small land-ownership structure, the lack of effective and efficient business formulas which render them poorly equipped to adapt to market changes.

In a situation where production costs are unlikely to be reduced, and in light of the intense competitiveness of the countries of North Africa, increases in profit margins can only be achieved through policies that promote products, favor product diversification, and enhance vertical and horizontal integration. Furthermore, the current market conditions of inputs (energy, labor, tilling, fertilizers, chemical products, transportation)

Table 1. Economic results of artichoke growing.

\begin{tabular}{lr}
\hline Items & \multicolumn{1}{c}{$€ /$ ha } \\
\hline $\begin{array}{l}\text { Tilling, setup and leveling } \\
\quad \text { of irrigation system }\end{array}$ & 780.00 \\
Purchase and planting & \\
$\quad$ of ovules & $3,071.00$ \\
Soil management & \\
Fertilizers & 300.00 \\
Irrigation & 346.50 \\
Crop treatments & 750.00 \\
Harvesting & 365.00 \\
Packaging & $3,650.00$ \\
Transport & $1,129.40$ \\
Mediation & $1,240.00$ \\
Maintenance and repairs & $1,764.00$ \\
$\quad$ of durable capital & 350.00 \\
Interest on current costs & 108.50 \\
Total variable costs & $13,854.40$ \\
Depreciation of durable capital & 850.00 \\
Administration expenses & 705.63 \\
Taxes & 559.72 \\
Interest on durable capital & $1,150.00$ \\
$\quad$ and land value & \\
Total fixed costs & $3,265.35$ \\
Total costs & $17,119.75$ \\
Gross production value & $17,640.74$ \\
Profit & 520.99 \\
Unit profit ( $€ /$ head) & 0.01 \\
\hline &
\end{tabular}

are all on the increase. On the demand side, with the economy in recession, incomes are reduced, driving consumers to opt for the more economical foreign artichokes over the national product. An increased profitability of artichokes requires that the whole sector be launched anew by way of integration strategies. The objective of horizontal integration is to expand the production of the same or similar products so as to increase market share, thus reducing competition. A means of integrating horizontally is via a buyout of a second farm or by expanding so as to increase one's market share by using economies of scale. In times of recession, successful companies are able to take over their struggling competitors on the cheap. Horizontal integration brings with it many advantages for companies able to expand effectively. However, hasty horizontal expansions without solid planning can easily lead to financial ruin. Expansions require mindful management and often entail revising the whole corporate strategy. However, taking over another business can lead to foreseeable problems such as excessive fixed costs that could determine a quandary for the business, if not adequately compensated by increases in sales.

Vertical integration has the goal of gaining control over all aspects of the production of a product or service. One viable strategy could be that of establishing a short supply chain (from the soil to market). However, the latter cannot absorb the entire production of a farm, but only a fraction of it.

In conclusion, the fragmented production and offer, together with the shortcomings of policies aiming to enhance products, lead to stagnation of agricultural activities, which inevitably lowers incomes and employment opportunities in the areas of reference. Economic sustainability is the prerequisite for 
long-term viability of any production process and, therefore, of any economic activity capable of creating opportunities for both employment and income.

\section{Literature Cited}

Ataseven, Y., M.O. Akça, and A. Namli. 2014. Farmers' attitudes towards soil analysis in Ankara province of Turkey. Fresenius Environmental Bulletin 23(8A):2038-2044.

Beckford, C., D. Campbell, and D. Barker. 2011. Sustainable food production systems and food security: Economic and environmental imperatives in yam cultivation in Trelawny, Jamaica. Sustainability $3: 541-561$.

Bonazzi, G. and M. Iotti. 2014. Interest coverage ratios (ICRs) and financial sustainability: Application to firms with bovine dairy livestock. Amer. J. Agr. Biol. Sci. 9(4):482-489.

Cecchini, M., A. Colantoni, R. Massantini, and D. Monarca. 2010. Estimation of the risks of thermal stress due to the microclimate for manual fruit and vegetable harvesters in central Italy. J. Agr. Saf. Health 16(3):141-159.

Chinnici, G., G. Pappalardo, and B. Pecorino. 2014. Economic evaluation of innovative solutions for food safety in cereal sector in Sicily. Quality-Access to Success 15(Suppl. 1):41-47.

Cirivello, T., P. Girgenti, M. Venezia, and C. Chiarello. 2005. Profitability of artichoke 'Spinoso violetto di Palermo' in the Menfi District (Sicily). Acta Hort. 681:181-188.
Conti, F., G. Abbate, A. Alessandrini, and C. Blasi. 2005. An annotated checklist of the Italian vascular flora. 1st ed. Palombi Ed, Roma.

D'Asaro, F. and G. Grillone. 2012. Empirical investigation of curve number method parameters in the Mediterranean area. J. Hydrol. Eng. 17(10):1141-1152.

Dana, L.P. and T.E. Dana. 2005. Expanding the scope of methodologies used in entrepreneurship research. Intl. J. Entrep. Small Bus. 2(1):79-88.

Del Nobile, M.A., A. Conte, C. Scrocco, J. Laverse, I. Brescia, G. Conversa, and A. Elia. 2009. New packaging strategies to preserve fresh-cut artichoke quality during refrigerated storage. Innov. Food Sci. Emerg. Technol. 10(1):128-133.

Engindeniz, S. 2007. Economic analysis of processing tomato growing: The case study of Torbali, west Turkey. Span. J. Agr. Res. 7(5):7-15.

FAO. 2015. FAO Statistics Division. 6 Jan. 2015. $<$ http://faostat.fao.org/site/291/default.aspx>.

Goubran, F., G. Hale, S. Salib, B. Tomkins, R. Clarke, and H. Hoffmann. 2005. The globe artichoke industry in Australia. Acta Hort. 681:483-488.

Iotti, M. and G. Bonazzi. 2014. Life cycle flow analysis: Methodological improvement and application to the Parma PDO ham sector. Quality-Access to Success 15(143):98-103.

ISTAT. 2015. Agricultural statistics. 6 Feb. 2015. $<$ http://www.istat.it $>$.

ISTAT. 2012. 6th General Agricultural Census. 6 Feb. 2015. <http://www.istat.it/it/censimentoagricoltura/agricoltura-2010>.

Lanfranchi, M., C. Giannetto, and A. Puglisi. 2014. A cost-benefits analysis for risk management in a biological farm. Appl. Math. Sci. 8(1316):775-787.

Lanfranchi, M. and C. Giannetto. 2014. Analysis of producers' knowledge about farmers' markets. Ital. J. Food Sci. 26(3):335-340.

Leskovar, D.I., C. Xu, and S. Agehara. 2013. Planting configuration and plasticulture effects on growth, physiology, and yield of globe Artichoke. HortScience 48:1496-1501.

Lupo, T. 2015a. Fuzzy ServPerf model combined with ELECTRE III to comparatively evaluate service quality of international airports in Sicily. J. Air Transp. Manage. 42:249-259.

Lupo, T. 2015b. Non-dominated "trade-off" solutions in television scheduling optimization. Intl. Trans. Oper. Res. 22(3):563-584.

Lupo, T. 2015c. The new Nino capability index for dynamic process capability analysis. Qual. Reliab. Eng. Intl. 31(2):305-312.

Messori, F. 2007. L'azienda Agraria. Introduzione all'economia dell'unità di produzione agricola, Clueb editrice, Bologna.

Monarca, D., R. Moscetti, L. Carletti, M. Cecchini, A. Colantoni, E. Stella, G. Menghini, S. Speranza, R. Massantini, M. Contini, and A. Manzo. 2014. Quality maintenance and storability of chestnuts manually and mechanically harvested. Acta Hort. 1043:145-152.

Prestamburgo, M. and V. Saccomandi. 1995. Economia Agraria, Etas libri, Mondadori, Milano.

Spiertz, H. 2013. Challenges for crop production research in improving land use, productivity and sustainability. Sustainability 5:16321644. 